\title{
A Comparative Study on the Wear Behaviors of Cladding Candidates
}

\section{for Accident-Tolerant Fuel}

\author{
Young-Ho Lee ${ }^{a, *}$ and Thak Sang Byun ${ }^{b}$ \\ ${ }^{a}$ Korea Atomic Energy Research Institute, Daejeon 305-353, South Korea/Visiting \\ Scientist at Oak Ridge National Laboratory \\ ${ }^{\mathrm{b}}$ Pacific Northwest National Laboratory, Richland WA 99354, USA(formerly at Oak \\ Ridge National Laboratory)
}

${ }^{*}$ Corresponding author. Address: 989-111 Daedeok-daero, Yuseong-gu, Daejeon 305-353, South Korea

Tel: +82-42-868-8761, E-mail address: leeyh@kaeri.re.kr (Y.-H. Lee)

\begin{abstract}
Accident-tolerant fuels are expected to have considerably longer coping time to respond to the loss of active cooling under severe accidents and, at the same time, have comparable or improved fuel performance during normal operation. The wear resistance of accident tolerant fuels, therefore, needs to be examined to determine the applicability of these cladding candidates to the current operating PWRs because the most common failure of 1 Fretting wear of ATF cladding candidates
Young-Ho Lee
\end{abstract}


nuclear fuel claddings is still caused by grid-to-rod fretting during normal operations. In this study, reciprocating sliding wear tests on three kinds of cladding candidates for accident-tolerant fuels have been performed to investigate the tribological compatibilities of self-mated cladding candidates and to determine the direct applicability of conventional Zirconium-based alloys as supporting structural materials. The friction coefficients of the cladding candidates are strongly influenced by the test environments and coupled materials. The wear test results under water lubrication conditions indicate that the supporting structural materials for the cladding candidates of accident-tolerant fuels need to be replaced with the same cladding materials instead of using conventional Zirconium-based alloys.

Keywords: Accident-tolerant fuel, Zirconium-based alloy, tribological property, material compatibility, reciprocating wear

\section{Introduction}

Since the Zirconium-based alloys exhibit excellent resistance to corrosion in high 
temperature water, a small neutron cross section, and acceptable mechanical properties under normal operating conditions, they have been successfully used as fuel cladding and structural materials of fuel assemblies in light water reactors (LWRs). As the corrosion resistance of $\mathrm{Zr}$ alloy claddings is directly related to nuclear fuel integrity, the development of advanced Zr-based alloys has been focused on further enhancing their corrosion resistance over the past two decades [1-4]. Experimental or fuel performance results in simulated or operating PWR conditions have demonstrated that the newly developed corrosion-resistant $\mathrm{Zr}$ alloys have led to a significant reduction of hydrogen pickup, hydride formation and cladding oxide layer thickness [5]. Under normal operating conditions, such improvement in fuel reliability, together with an effective fuel management program, enables fuel vendors and utilities to achieve high-burnup $\mathrm{Zr}-\mathrm{UO}_{2}$ fuel system, and to maintain a negligible fuel failure rate of the order of a few ppm per year [6].

Considering that the most common fuel failure is still caused by grid-to-rod fretting (GTRF), however, the alloying elements in advanced $\mathrm{Zr}$ alloys influenced the fretting wear resistance to a lesser degree. Previous studies indicated that the mechanism of GTRF degradation has a strong dependence on the grid-to-rod gap as a function of burnup, especially in the presence of high flow rates (i.e., excessive flow-induced vibration) [7-12]. 
Even though the new design features for enhancing the wear-resistance of spacer grids with the same $\mathrm{Zr}$ alloys have significantly increased the reliability of nuclear fuels, the grid-torod gap can be gradually increased by cladding creep-down and spacer grid strip growth, and is still an unavoidable phenomenon under high neutron irradiation and operating temperature.

The recent nuclear disaster at Fukushima Dai-ichi reactors has led to an overall reappraisal of the traditional $\mathrm{Zr}-\mathrm{UO}_{2}$ fuel system under design-basis accident (DBA) and beyond design-basis accident (BDBA) scenarios [13-15]. As a result, there is a growing consensus of opinion on developing a new fuel system (i.e., accident-tolerant fuel, ATF), that can increase the coping time to respond to severe accidents. The ATF could be defined as a new fuel/cladding system with enhanced accident tolerance to loss of active cooling in the core for a considerably longer time period under severe accidents while maintaining or improving the fuel performance during normal operations [16-18]. The major candidates of ATF system included a fully ceramic micro-encapsulated (FCM) fuel pellet embedded in silicon carbide (SiC) matrix [19-22], cladding materials with SiC composite [23-26], various Fe-based alloys with high oxidation resistance [16, 27] and surface coating technology of current $\mathrm{Zr}$ alloys [28] for enhancing their corrosion resistance in high 
temperature steam. Under normal operating and/or under simulated DBA and BDBA conditions, their fuel performance and corrosion resistance were extensively analyzed and evaluated by focusing on the variation of the peak cladding temperature, hydrogen generation and their oxidation behavior in comparison with the traditional $\mathrm{Zr}-\mathrm{UO}_{2}$ system.

When considering that these ATF cladding candidates are applied to current Zr-based fuel assemblies (FAs) without any changes or with partial changes of design features, some critical issues, which are expected to happen, should be reviewed at the initial development stage. This is because the goal of ATF is to insert a lead test assembly (LTA) or a lead test rod (LTR) into a commercial reactor in the next few years [29]. For instance, it is necessary to confirm whether current spacer grids with Zr-based alloys could accommodate new cladding materials of ATF without any significant degradation such as GTRF and galvanic corrosions between dissimilar materials. In particular, in the case of GTRF [30], the tribological properties of new ATF materials against conventional $\mathrm{Zr}$ alloys and self-mated ATF materials are not fully understood. The objective of this study, therefore, is to examine the frictional behavior of ATF candidate materials focusing on the compatibilities of material combinations as well as the variation of wear mechanism under reciprocating sliding conditions, in comparison with conventional $\mathrm{Zr}$ alloys. 


\section{Experimental Procedure}

For this study, three kinds of ATF cladding candidates and a conventional Zr-based alloy with a nominal outer diameter of $9.5 \mathrm{~mm}$ and a length of $6 \mathrm{~mm}$ were prepared and tested. Surface roughness of each sample was maintained at about $0.3 \mu \mathrm{m}$. Table 1 summarizes the information of the specimen groups including the sample I.D., top and bottom materials, and mechanical properties of the tested materials. The friction and wear tests were carried out on a reciprocating sliding tester, working with a tube-on-tube geometry arranged at a right angle. A schematic diagram is shown in Fig. 1. All reciprocating wear tests were performed in room temperature range $\left(24-27{ }^{\circ} \mathrm{C}\right.$ ) in unlubricated (air) condition and in water lubrication. The reciprocating stroke and number of total cycles were fixed at $1 \mathrm{~mm}$ and $1 \times 10^{5}$, respectively. Contact normal forces of 2,5 , and $10 \mathrm{~N}$ were applied to the specimen couples at oscillation frequencies of 5, 15, and $30 \mathrm{~Hz}$. During the tests, the coefficient of friction (COF) was continuously monitored to examine the relationship between the variations of the COF curve and wear amount of each specimen. After the wear tests, the worn surface of each sample was observed using a surface profilometer for measuring the wear depth profile. In addition, the variation of the frictional behaviors with 
increasing applied load and oscillation frequency was examined by focusing on the effect of the material combination on the wear behavior of the ATF candidate materials.

\section{Results and discussion}

\subsection{Wear depth}

Wear depths are obtained from both the top and bottom samples after the reciprocating sliding wear tests. Figs. 2 and 3 describe the measurement results of the maximum wear depth with a contact force and frequency in ATF candidate-Zr alloy couples (i.e., DF, DN, and DS samples). In this result, the enlarged difference in wear depth of both tube samples is considered as one-side localized wear among the tube samples, which should be avoided by a suitable material selection for enhancing the wear resistance. The depth results of selfmated $\mathrm{Zr}$ alloy (i.e., SZ sample) were also included for comparing the wear behavior with those of DF, DN, and DS samples.

The wear depth in an unlubricated condition (i.e., in air) was weakly dependent on the ATF cladding candidates; no significant difference was found in the wear depth increase in Fe-based alloys, FCA, and NFA, when compared to the SiC sample showing a relatively smaller wear depth. However, the measured wear depths are always higher for $\mathrm{Zr}$ alloys 
than for all ATF cladding candidates. This indicates that more wear debris are associated with $\mathrm{Zr}$ oxides because their formation is expected to accelerate by frictional heat in unlubricated conditions. With increasing the number of cycles, the wear mechanism is expected to progress by a third-body abrasion of $\mathrm{Zr}$ oxides between contact surfaces. Therefore, the effect of their mechanical properties gradually disappeared when much of the contacting surface is covered with wear debris of coupled $\mathrm{Zr}$ alloys, which could decrease the possibility of direct contact between the ATF candidates and coupled Zr alloys. Under water lubrication, however, the wear depth of both the ATF candidates and coupled $\mathrm{Zr}$ alloy has a strong dependency on their mechanical properties as shown in Fig. 3. When comparing the results of self-mated $\mathrm{Zr}$ alloys, the wear depths of the ATF cladding candidates have much smaller values, but those of $\mathrm{Zr}$ alloys increased considerably with increasing mechanical strength of the ATF candidates. This result indicates that severe plastic deformation and localized wear were concentrated on the coupled $\mathrm{Zr}$ alloy, which has relatively weak mechanical properties. In addition, the wear debris generated in the frictional process is expected to be immediately removed from the contact surface under water lubrication. Therefore, the excessive increase of wear depth in the coupled $\mathrm{Zr}$ alloy specimens could be explained by the effect of high mechanical strength in coupled ATF 
candidates.

Figs. 4 and 5 compare the measurements of wear depths in self-mated ATF cladding candidates (i.e., SF, SN, and SS). As expected, no significant wear depth was found in all tested conditions except for the Fe-based alloys in unlubricated condition. In addition, the wear depth of the ATF cladding candidates could be negligible when compared to the result of self-mated $\mathrm{Zr}$ alloys. Generally, the wear progress could be described by a severe surface or subsurface deformation, debris detachment by a fracture of the deformed layer and the formation of a wear debris layer or final release from a worn surface [8, 31]. These indicate that the ATF cladding candidates can accommodate the contact loads and frequencies applied in this study without severe plastic deformation due to their outstanding mechanical strengths. However, the mechanical properties of the FCA and $\mathrm{Zr}$ alloy samples are comparable, and therefore the effects of debris in unlubricated condition are expected to share many similarities with the wear behavior of $\mathrm{Zr}$ alloys. To verify the effect of wear debris, it is necessary to examine the frictional behavior of each coupled material condition.

\subsection{Friction behavior}

Fig. 6 shows the representative frictional behaviors between ATF cladding candidates 
and a coupled $\mathrm{Zr}$ alloy. Regardless of the different test environments, the coefficients of friction $(\mathrm{COF})$ of the tested material conditions gradually decreased with increasing contact load and frequency. Also, the mean COF values under water lubrication are relatively lower than that in unlubricated condition. In unlubricated condition with a contact load of $2 \mathrm{~N}$ and frequency of $5 \mathrm{~Hz}$, the initial COF shows a small value, but increases rapidly with the number of cycles and then saturates after few thousand cycles. An interesting point is that the instabilities of the COF curves were clearly shown in all tested conditions, and these behaviors continued to the end of the cycles. With increasing applied load and frequency, however, an irregular COF drop initiated under specific material conditions; then, these instabilities disappeared gradually.

If the wear debris detached from contacting surface remains on the surface in unlubricated condition, a worn surface may become more and more irregular and then smaller wear debris could be agglomerated in suitable positions on the irregular worn surface, which could easily form a wear debris layer. Thus, the instabilities and irregular drops of COF curves are closely related to the wear debris interaction between the contact surfaces and fracture of wear-debris layer, respectively. At low contact force and frequency, the generated wear debris can be easily remained between contact surfaces without severe 
agglomeration to form wear-debris layers. However, it is expected that these layers can be well-developed with increasing contact load and frequency. Thus, the irregular drop of the COF curves can be explained by the repeated fracture and formation of wear-debris layers. When comparing the wear depth results, the more instable and irregular behavior of the COF curve, the higher the increase of wear depth.

Under water lubrication, there is no significant change in COF value with increasing number of cycle. The instabilities and irregular drops in each COF curve still appeared under relatively low load and frequency conditions, but these unstable behaviors of Febased alloys gradually disappeared with the increase of contact load and frequency. However, the COF curve of the SS condition increased gradually and then saturated at about 0.4 with the initiation of irregular behaviors. In ATF candidates against Zr alloy, a dominant factor for determining the wear behavior is considered as a severe plastic deformation between contacting surfaces, which was determined by the extent of the instability and mean values in the COF curve.

Fig. 7 shows the variation of the COF curves of self-mated ATF candidates compared with the curves of ATF candidates against $\mathrm{Zr}$ alloy. In unlubricated condition, the COFs of Fe-based alloys (i.e., SF and SN) dramatically increased up to about 1, but gradually 
decreased with applied load and frequency. However, there is little change in the COF curve of the SS sample and their values remained at about 0.2-0.4. An interesting point was that, with increasing applied load and frequency, the COF curve of the SF sample became unstable with decreasing mean COF value, but the initial unstable curve portions of SN sample gradually disappeared. In the SS sample, however, the initial COF curve shows unstable behavior with large fluctuation, but it shows a stable behavior at high cycles. Therefore, the frictional behaviors of each self-mated ATF material is strongly affected by the wear debris compositions determined by each material composition. Also, these results are a good correlation with the wear depth results, which can be explained by the relationship between the wear debris behaviors and irregular and/or repeated drop of COF curves.

Under water lubrication, the frictional behaviors of self-mated materials are easily distinguished for their saturated and stable friction curves. In lower contact force and frequency regions, the initial COF values of SF and SN samples rapidly increased and then saturated at about 0.7 and 0.4 , respectively. However, that of the SS sample saturated at below 0.2 at higher cycles. Under the test variables, therefore, the generation rate of the wear debris after severe plastic deformation is expected to gradually decrease with cycles 
due to their relatively high mechanical properties and smaller COF values. Consequently, the self-mated ATF materials have more wear-resistances than those coupled with $\mathrm{Zr}$ alloy and conventional self-mated $\mathrm{Zr}$ alloy.

\subsection{Contact area}

Fig. 8 displays the typical measurement results of the contact area at an applied force of $10 \mathrm{~N}$ and frequency of $30 \mathrm{~Hz}$. The contact area of the ATF cladding candidates is strongly dependent on both the test environments and coupled materials; in the dissimilar materials of DF, DN, and DS, no significant difference of both top and bottom contact areas was found in unlubricated condition regardless of their different mechanical properties. Thus, the formation of a contact area with depth is affected by the interaction of the wear debris, which is mainly detached from the coupled $\mathrm{Zr}$ alloy. This dependence of the debris behavior on the formation of contact area is consistent with the wear depth results shown in Fig. 2. Under water lubrication, however, the worn area was strongly dependent on the bulk hardness of the ATF candidates. When compared with the wear depth results, it is believed that the wear behaviors can be distinguished from the adhesive wear (i.e., DF sample) to excess abrasive wear (i.e., DS sample). Therefore, the key factor determining the wear 
behavior of the DF, DN, and DS samples is considered to be wear debris behavior, which was mainly detached by the deformed surfaces of $\mathrm{Zr}$ alloy, and the difference in bulk hardness of the ATF candidates, which could determine the wear mechanism in unlubricated and water lubrication, respectively.

As discussed above, the wear depths of both the top and bottom specimens were closely associated with their mechanical properties in self-mated ATF candidates. Under the same test condition, the amount of severe plastic deformation between the contacting surfaces is dependent on the mechanical strength, even though the coefficient of friction depends on the contacting materials. If the test material has high mechanical strength, further deformation of the deformed layer and the final formation of the wear debris will be reduced. Therefore, the ATF candidates with a relatively high mechanical strength show negligible sizes of contact area under water lubrication. In unlubricated condition, however, the amount of wear debris is expected to increase with decreasing their bulk hardness. Furthermore, the oxidized wear debris easily accelerates severe wear between contacting surfaces by third-body abrasion when the ATF candidates have relatively low bulk hardness values. Thus, it is believed that the contact area in a self-mated material is highly sensitive to its mechanical strength. 


\subsection{Materials compatibilities}

In current operating PWRs, nuclear fuel rods frequently suffer from grid-to-rod fretting (GTRF) at contacting points of spacer grids under flow-induced vibration (FIV). Although such degradation can be minimized by improving the spacer grid design of Zr-based alloys, it is difficult to apply current technologies of the spacer grid design to the supporting structures for ATF cladding candidates. This is because the wear behavior is basically controlled by their tribological properties, vibration behaviors under FIV, and changes of their metallurgical and mechanical characteristics under irradiation and temperature.

As shown in the wear test results for coupled dissimilar materials, the wear behavior of Zr-based alloy, which is considered as a spacer grid material, can be accelerated by ATF cladding candidates with relatively high mechanical strengths. Under water lubrication, the bulk hardness difference between the tested materials is one of the key factors for determining the wear behaviors between ATF cladding candidates and $\mathrm{Zr}$ alloys. Moreover, the GTRF phenomenon was strongly affected by the grid-to-rod gap under FIV [12], which results in more impacting motion combined with sliding motion against spacer grids. If wear progress is concentrated on the surface of $\mathrm{Zr}$ alloy and thus the wear depth of ATF 
cladding candidates is negligible, excessive wear depth should be associated with a significant loss of contact force between the fuel rod and its spacer grid, which results in an enlarged grid-to-rod gap. Note that the difference in wear depth in Figs. 2-5 could be considered as one of the key factors for evaluating the "material compatibility" to select suitable materials as a supporting structure. Therefore, if the Zr-based alloys are applied as the major structure materials for supporting an ATF cladding candidate, it is expected that a high resistance to GTRF degradation cannot be archived under normal operating conditions of PWRs. Based on the wear test results of self-mated ATF cladding candidates, however, the wear depths are always negligibly small under both unlubricated and water lubrications. This means that the structural materials for the fuel assembly of ATF should have similar mechanical properties of ATF cladding candidates.

As mentioned above, the primary objective of this wear study was to identify the applicability of Zr-based alloys to ATF cladding candidates as major structural materials. The test results indicate that Zr-based alloys need to be reexamined to use as spacer grid materials for ATF without remarkable improvements in their mechanical properties. In order to increase the wear resistance of Zr-based alloys, surface coating technology with a thin hard-surface layer, multilayered sandwich designs with a high strengthen alloy, and 
surface texturing for reducing COF can be considered. When the same materials of ATF cladding candidates are used as supporting structures in a fuel assembly, there still remain many issues to be resolved; for example, the effect of irradiation hardening and embrittlement on the impact strength of the spacer grid, high thermal neutron absorption cross section, impact of CRUD generation on the thermal conductivity, formability and fabricability of spacer grid spring/dimple, dynamic characteristics of fuel assembly with new materials, and weldability between structural parts, should be considered for a successful application of the new Fe-based alloys and/or silicon carbide fiber-reinforced $\mathrm{SiC}$ matrix ceramic composites $(\mathrm{SiC} / \mathrm{SiC})$.

\section{Summary and conclusion}

The wear behaviors of candidate accident-tolerant fuel cladding materials against $\mathrm{Zr}$ based alloy and the same materials couples have been studied using a reciprocating sliding wear tester at room temperature under unlubricated and water lubrication conditions. The main objective of this study was to examine the applicability of Zr-based alloy and candidate ATF cladding materials while maintaining or improving the resistance to grid-torod fretting degradation. The wear resistance between the pairs of dissimilar and the same 
materials were evaluated in terms of wear depth and frictional behavior. The new findings are summarized as follows:

(1) With a supporting structure of Zr-based alloy, no significant variation in wear depth was found among the candidate accident-tolerant fuel (ATF) claddings in unlubricated condition, regardless of the difference in their mechanical properties. However, the wear depth with water lubrication was strongly dependent on the bulk hardness of ATF candidates, and severe plastic deformation and localized wear were concentrated on the surface of coupled $\mathrm{Zr}$ alloy sample with relatively weak hardness.

(2) Within the test variables the ATF cladding candidates did not induce severe plastic deformation due to their high mechanical strength, which also resulted in negligible sizes of the contact area under water lubrication. The damage in FeCrAl alloy, however, has a strong dependence on the wear debris behavior in unlubricated condition, which has a similarity with the wear behavior in the same $\mathrm{Zr}$ alloy coupling since their mechanical properties are comparable.

(3) The test results indicate that it might be difficult to achieve proper resistance to GTRF degradation in normal operating condition if the current Zr-based alloys are 
still used as the major materials for supporting a new ATF cladding. As a key conclusion, therefore, it is suggested that either the mechanical properties of $\mathrm{Zr}$ alloy be improved to match that of the ATF cladding or, at a minimum the support structure, i.e., the grid, needs to be replaced with the same material as that of ATF cladding.

\section{Acknowledgements}

This research was supported by a National Research Foundation of Korea (NRF) grant by the Korean Government (Ministry of Science, ICT and Future Planning) (No. 2012M2A8A5025825). This research was co-sponsored by the Fuel Cycle R\&D program of the Office of Nuclear Energy, U.S. Department of Energy, under Contract DE-AC0500OR22725 with UT-Battelle, LLC. The friction wear testing has been performed at Oak

Ridge National Laboratory and the surface examination and detailed analysis at Korea Atomic Energy Research Institute.

\section{References}

[1] G. Wikmark, L. Hallstadius, K. Yueh, Nucl. Eng. Tech. 41 (2009) 143-148. 
[2] P. Bossis, D. Pecheur, K. Hanifi, J. Thomazet, M. Blat, J. ASTM Int. 3 (2006) 494-525.

[3] G. Pan, C.J. Long, A.M. Garde, A.R. Atwood, J.P. Foster, R.J. Comstock, L. Hallstadius,

D.L. Nuhfer, in: Proceedings of 2010 LWR Fuel Performance, Paper 74, ANS (2010).

[4] Y.H. Jeong, S.Y. Park, M.H. Lee, B.K. Choi, J.H. Baek, J.Y. Park, J.H. Kim, H.G. Kim,

Nucl. Sci. Tech. 43 (2006) 977-983.

[5] T.R. Allen, R.J.M. Konings, A.T. Motta, "5.03 Corrosion of Zirconium Alloys", in

Comprehensive Nucl. Mater., edited by J. M. K. Editor-in-Chief: Rudy (Elsevier, Oxford), (2012) 49-68.

[6] K. Edsinger, Nucl. News 53 (2010) 40.

[7] P.R. Rubiolo, Nucl. Eng. Des. 236 (2006) 1628-1640.

[8] Y.H. Lee, H.K. Kim, Wear 263 (2007) 451-457.

[9] S. Kovacs, J. Stabel, M. Ren, B. Ladouceur, Wear 266 (2009) 194-199.

[10] P.R. Rubiolo, M.Y. Young, Nucl. Eng. Des. 230 (2009) 68-79.

[11] J. Yan, K. Yuan, E. Tatli, Z. Karoutas, Nucl. Eng. Des. 241 (2011) 2974-2982.

[12] Y.H. Lee, H.K. Kim, Wear 301 (2013) 569-574.

[13] E.D. Blandford, J. Ahn, Elements 8 (2012) 189.

[14] J. Gulliford, in: Proceedings of OECD/NEA Workshop Accident Tolerant Fuels of 20 
LWRs. OECD/NEA, Issy-les-Moulineaux, France, 2012.

[15] J. Hercezeg, in: Symposium of Advanced LWR Fuels, CANES-MIT, Cambridge, MA, 2012.

[16] S.J. Zinkle, K.A. Terrani, J.C. Gehin, L.J. Ott, L.L. Snead, J. Nucl. Mater. 448 (2014) 374-379.

[17] L.J. Ott, K.R. Robb, D. Wang, J. Nucl. Mater. 448 (2014) 520-533.

[18] J. Carmack, F. Goldner, S.M. Bragg-Sittona, L.L. Snead, in: Proceedings of 2013 LWR Fuel Performance Meetings, ANS, Charlotte, NC, 2013, Paper 8547.

[19] K.A. Terrani, J.O. Kiggans, L.L. Snead, J. Nucl. Mater. 427 (2012) 79-86.

[20] K.A. Terrani, J.O. Kiggans, Y. Katoh, K. Shimoda, F.C. Montgomery, B.L. Armstrong, C.M. Parish, T. Hinoki, J.D. Hunn, L.L. Snead, J. Nucl. Mater. 426 (2012) 268-276.

[21] K.A. Terrani, L.L. Snead, J.C. Gehin, J. Nucl. Mater. 427 (2012) 209-224.

[22] L.L. Snead, K.A. Terrani, Y. Katoh, C. Silva, K.J. Leonard, A.G. Perez-Bergquist, J. Nucl. Mater. 448 (2014) 389-398.

[23] K. Yueh, K.A. Terrani, J. Nucl. Mater. 448 (2014) 380-388.

[24] M. Ben-Belgacem, V. Richet, K.A. Terrani, Y. Katoh, L.L. Snead, J. Nucl. Mater. 447 (2014) 125-142. 
[25] Y. Katoh, L.L. Snead, T. Cheng, C. Shih, W.D. Lewis, T. Koyanagi, T. Hinoki, C.H.

Henager, M. Ferrairs, J. Nucl. Mater. 448 (2014) 497-511.

[26] E.D. Herderick, K. Cooper, N. Ames, Adv. Mater. Processes 170 (2012) 24.

[27] K.A. Terrani, S.J. Zinkle, L.L. Snead, J. Nucl. Mater. 448 (2014) 420-435.

[28] Y.H. Koo, J.H. Yang, J.Y. Park, K.S. Kim, H.G. Kim, D.J. Kim, Y.I. Jung, K.W. Song, Nucl. Tech. 186 (2014) 295-304.

[29] S.M. Bragg-Sitton, L. Braase, R. Montgomery,C.R. Stanek, R.H. Montgomery, L.J. Ott, L.L. Snead, M.C. Billone, in: Proceedings of 2013 LWR Fuel Performance Meetings, ANS, Charlotte, NC, 2013, Paper 8419.

[30] J. F. Kelly, H. Druenne, Progress in Nucl. Energy 70 (2014) 266-269.

[31] H.K. Kim, Y.H. Lee, K.H. Lee, Nucl. Eng. Des. 238 (2008) 3321-3330. 
$\underline{\text { Table Captions }}$

Table 1 Mechanical properties and wear test matrices for ATF cladding candidates and a conventional $\mathrm{Zr}$ alloy. 


\section{Figure Captions}

Fig. 1. Schematic view of a reciprocating wear tester.

Fig. 2. Wear depth as a function of contact force and frequency in unlubricated condition between dissimilar materials: (a) FeCrAl alloy-Zr-based alloy; (b) Nano-structured ferritic Alloy-Zr-based alloy; (c) SiC/SiC composite-Zr-based alloy; (d) Self-mated Zr-based alloys for comparison.

Fig. 3. Wear depth as a function of contact force and frequency under water lubrication between dissimilar materials: (a) FeCrAl alloy-Zr-based alloy; (b) Nano-structured ferritic Alloy-Zr-based alloy; (c) SiC/SiC composite-Zr-based alloy; (d) Self-mated Zr-based alloys for comparison.

Fig. 4. Wear depth as a function of contact force and frequency in unlubricated condition between self-mated materials: (a) FeCrAl alloys; (b) Nano-structured ferritic Alloys; (c) $\mathrm{SiC} / \mathrm{SiC}$ composites. 
Fig. 5. Wear depth as a function of contact force and frequency under water lubrication between self-mated materials: (a) FeCrAl alloys; (b) Nano-structured ferritic Alloys; (c) $\mathrm{SiC} / \mathrm{SiC}$ composites.

Fig. 6. Variation of coefficient of friction (COF) curves with increasing contact force and frequency between dissimilar materials: in (a) unlubricated and (b) water lubrication conditions.

Fig. 7. Variation of coefficient of friction (COF) with increasing contact force and frequency between self-mated materials: in (a) unlubricated and (b) water lubrication conditions.

Fig. 8. Measurement results of contact area at each material combination at a contact force of $10 \mathrm{~N}$ and a frequency of $30 \mathrm{~Hz}$ : in couples of (a) dissimilar and (b) self-mated materials. 
Table 1 Mechanical properties and wear test matrices for ATF cladding candidates and a conventional Zr alloy.

\begin{tabular}{|c|c|c|c|c|c|c|}
\hline \multicolumn{3}{|c|}{ Materials } & Sample I.D. & Hardness & Yield strength & UTS \\
\hline \multicolumn{3}{|c|}{$\begin{array}{c}\text { FeCrAl alloy } \\
(\mathrm{Fe}-21.2 \mathrm{Cr}-5.2 \mathrm{Al}-0.15 \mathrm{Mn}-0.19 \mathrm{Si}-0.028 \mathrm{C})\end{array}$} & FCA & $225[\mathrm{HV}]$ & $475 \mathrm{MPa}$ & $687 \mathrm{MPa}$ \\
\hline \multicolumn{3}{|c|}{$\begin{array}{l}\text { Nano-structured Ferritic Alloy } \\
\left(\mathrm{Fe}-9.9 \mathrm{Cr}-2 \mathrm{~W}-0.37 \mathrm{Ti}-0.18 \mathrm{~V}-0.06 \mathrm{C}-0.3 \mathrm{Y}_{2} \mathrm{O}_{3}\right)\end{array}$} & NFA & $290[\mathrm{HV}]$ & $780 \mathrm{MPa}$ & $1,100 \mathrm{MPa}$ \\
\hline \multicolumn{3}{|c|}{$\mathrm{SiC} / \mathrm{SiC}$ composite } & $\mathrm{SiC}$ & $450[\mathrm{HV}]$ & N/A & N/A \\
\hline \multicolumn{3}{|c|}{$\begin{array}{l}\text { Commercial Zr-based Alloy } \\
\text { (Zr-1.5Sn-0.2Fe-0.1Cr) }\end{array}$} & $\mathrm{ZrA}$ & $177[\mathrm{HV}]$ & $\sim 420 \mathrm{MPa}$ & $\sim 520 \mathrm{MPa}$ \\
\hline Materials & Top sample & Bottom sample & Test I.D. & & Rem & \\
\hline \multirow{3}{*}{ Dissimilar } & FCA & $\mathrm{ZrA}$ & DF & \multirow{3}{*}{\multicolumn{3}{|c|}{$\begin{array}{l}\text { - FCA \& ZrA: Tube with } 9.5 \mathrm{~mm} \text { OD } \\
\text { - NFA \& SiC: Cylinder with } 9.5 \mathrm{~mm} \text { OD }\end{array}$}} \\
\hline & NFA & $\mathrm{ZrA}$ & $\mathrm{DN}$ & & & \\
\hline & $\mathrm{SiC}$ & $\mathrm{ZrA}$ & DS & & & \\
\hline \multirow{4}{*}{ Self-mated } & FCA & FCA & SF & \multirow{3}{*}{\multicolumn{3}{|c|}{$\begin{array}{l}\text { - Actuated materials: Top specimen } \\
\text { - Fixed material: Bottom specimen }\end{array}$}} \\
\hline & NFA & NFA & SN & & & \\
\hline & $\mathrm{SiC}$ & $\mathrm{SiC}$ & SS & & & \\
\hline & $\mathrm{ZrA}$ & $\mathrm{ZrA}$ & SZ & \multicolumn{3}{|c|}{ - Reference data } \\
\hline
\end{tabular}




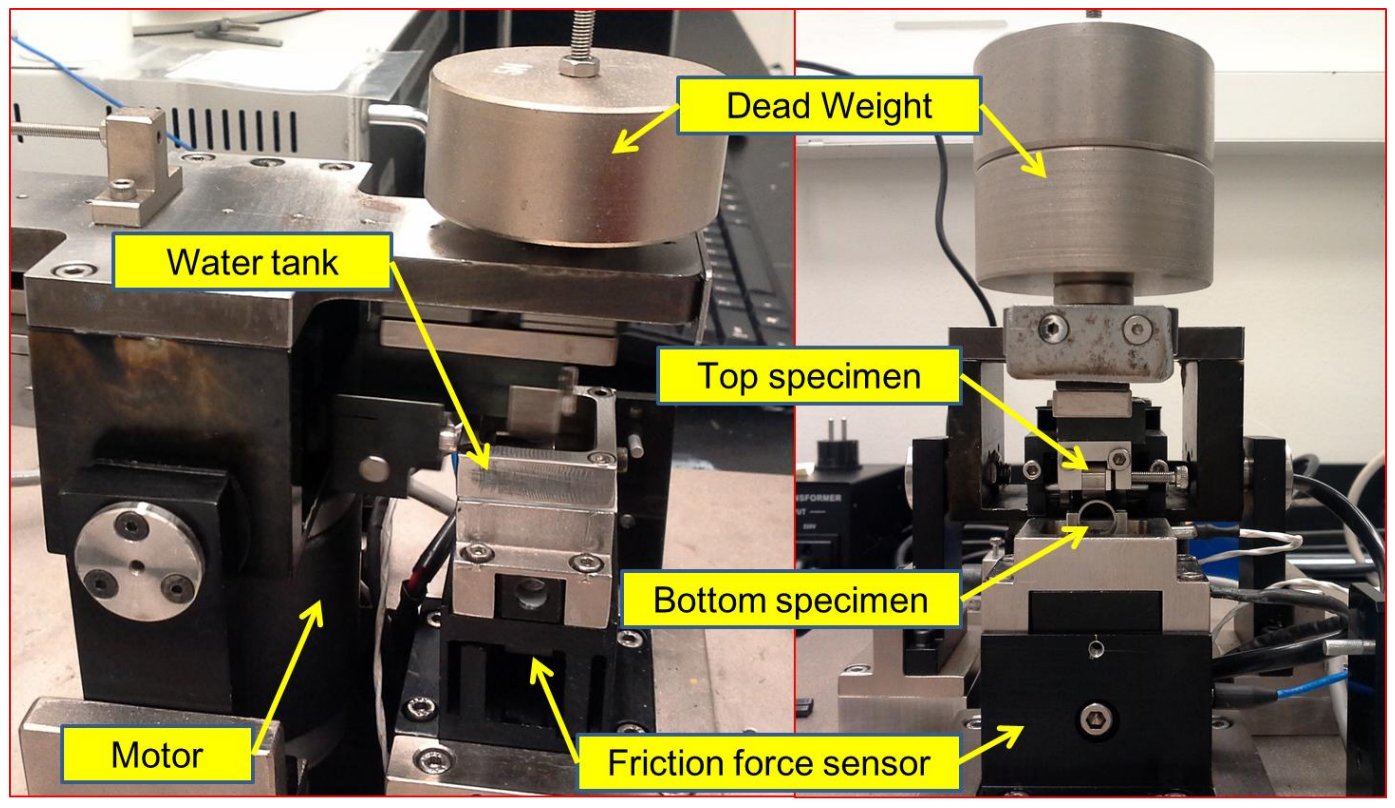

Fig. 1. Schematic view of a reciprocating wear tester. 
(a)

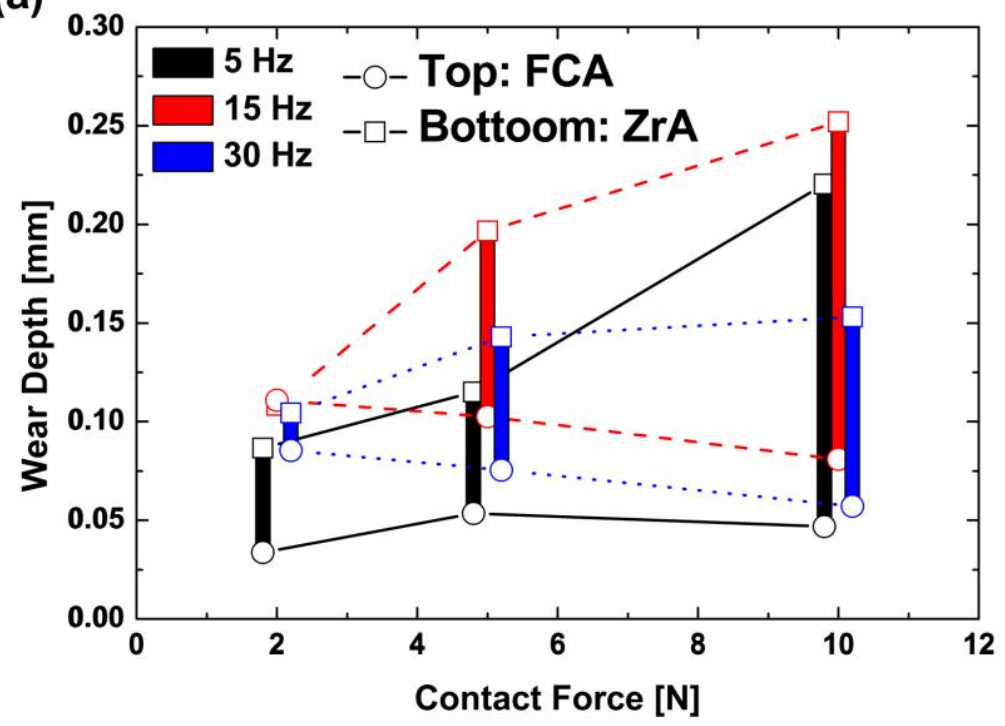

(b)

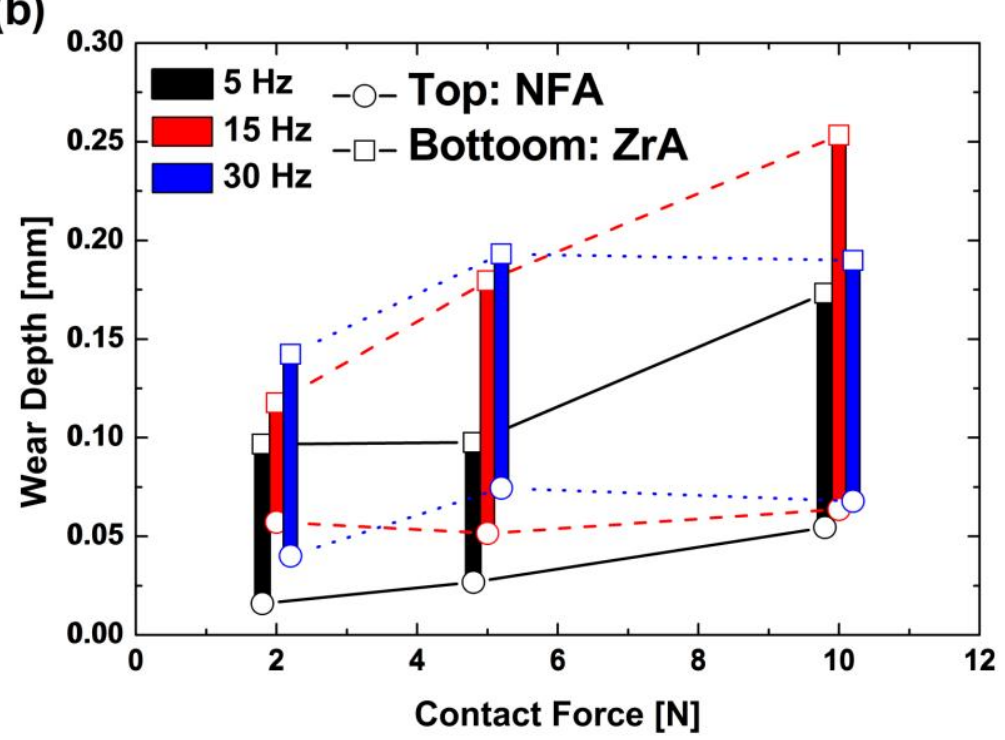



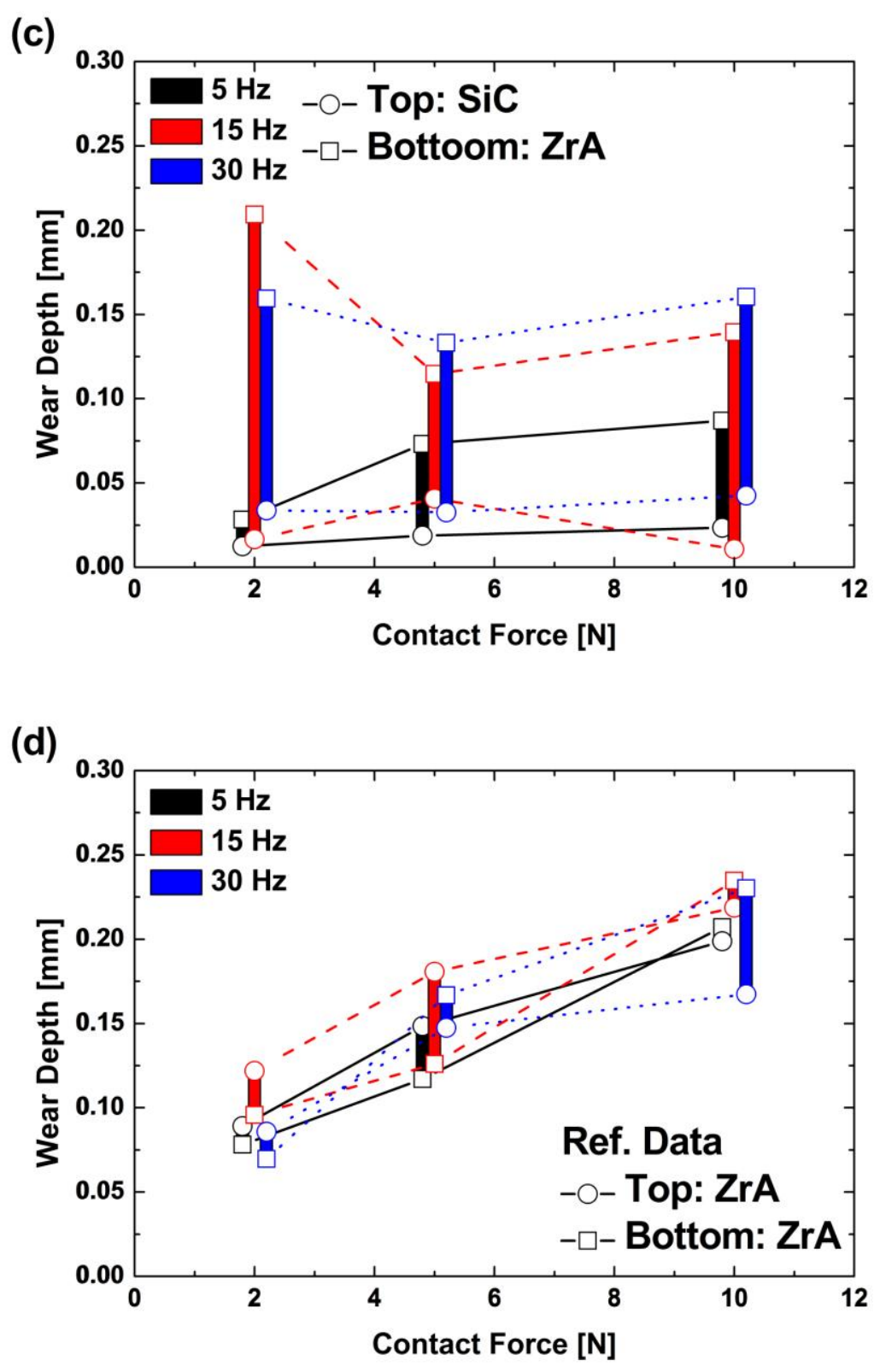

Fig. 2. Wear depth as a function of contact force and frequency in unlubricated condition between dissimilar materials: (a) FeCrAl alloy-Zr-based alloy; (b) Nano-structured ferritic Alloy-Zr-based alloy; (c) SiC/SiC composite-Zr-based alloy; (d) Self-mated Zr-based alloys for comparison. 
(a)

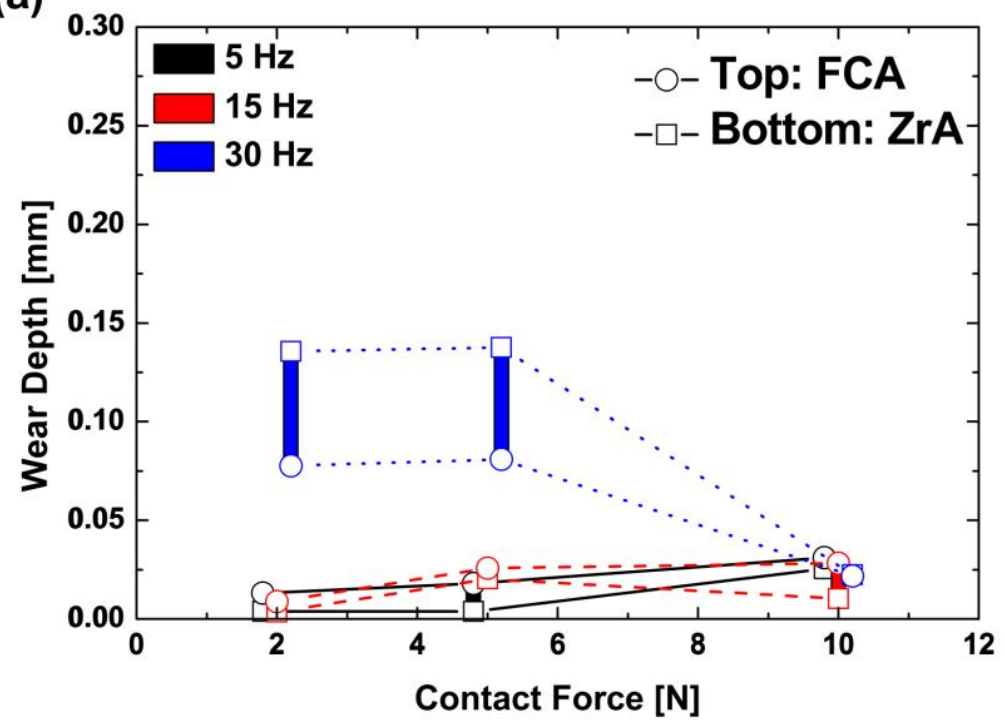

(b)

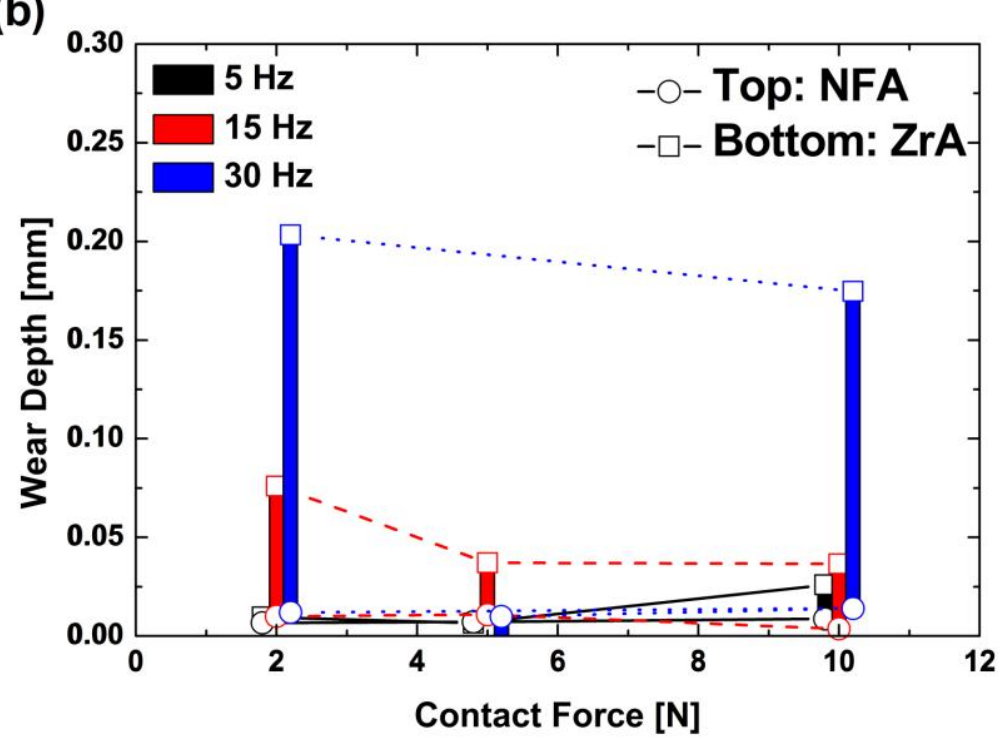



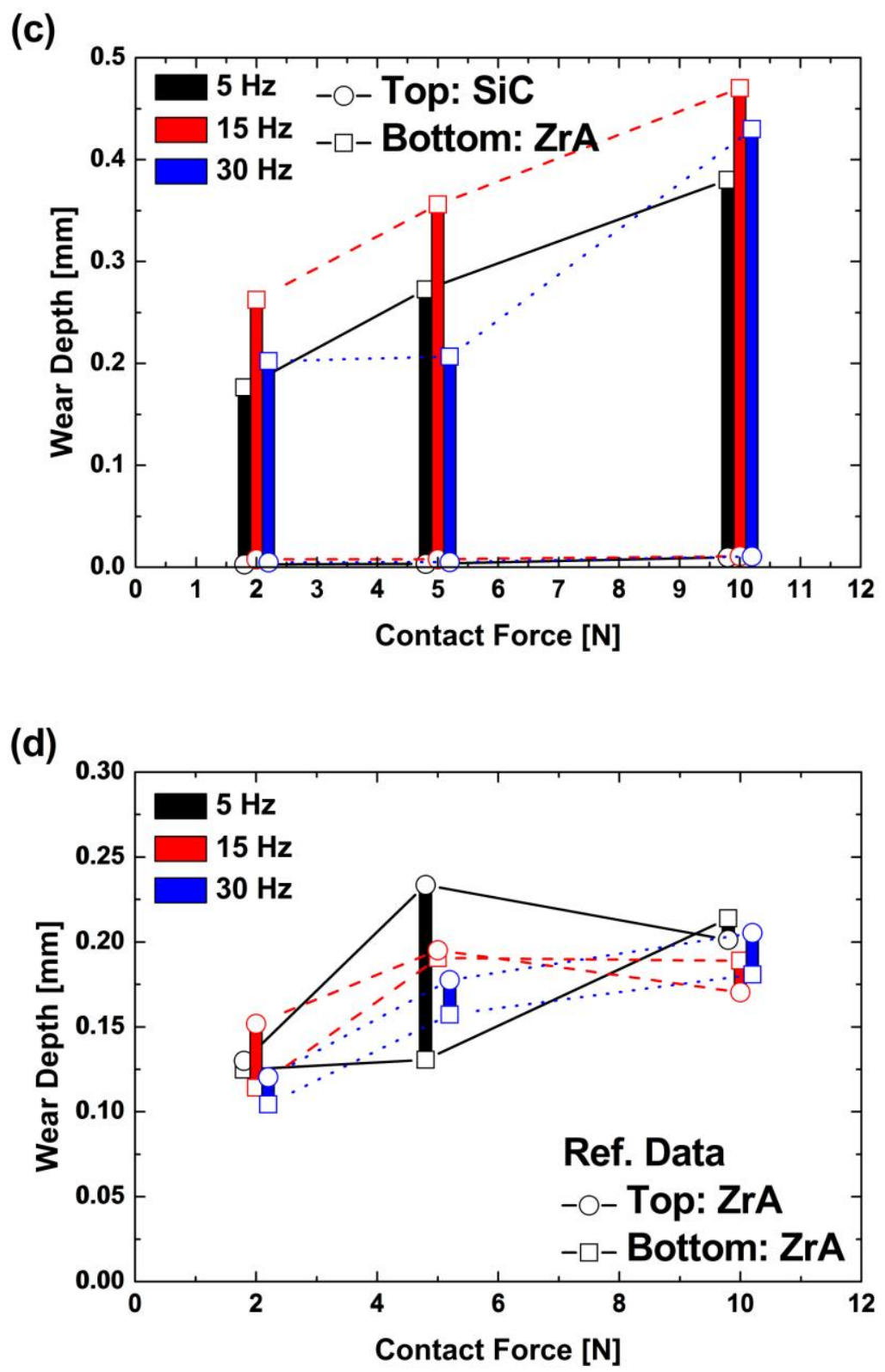

Fig. 3. Wear depth as a function of contact force and frequency under water lubrication between dissimilar materials: (a) FeCrAl alloy-Zr-based alloy; (b) Nano-structured ferritic Alloy-Zr-based alloy; (c) $\mathrm{SiC} / \mathrm{SiC}$ composite-Zr-based alloy; (d) Self-mated Zr-based alloys for comparison. 
(a)

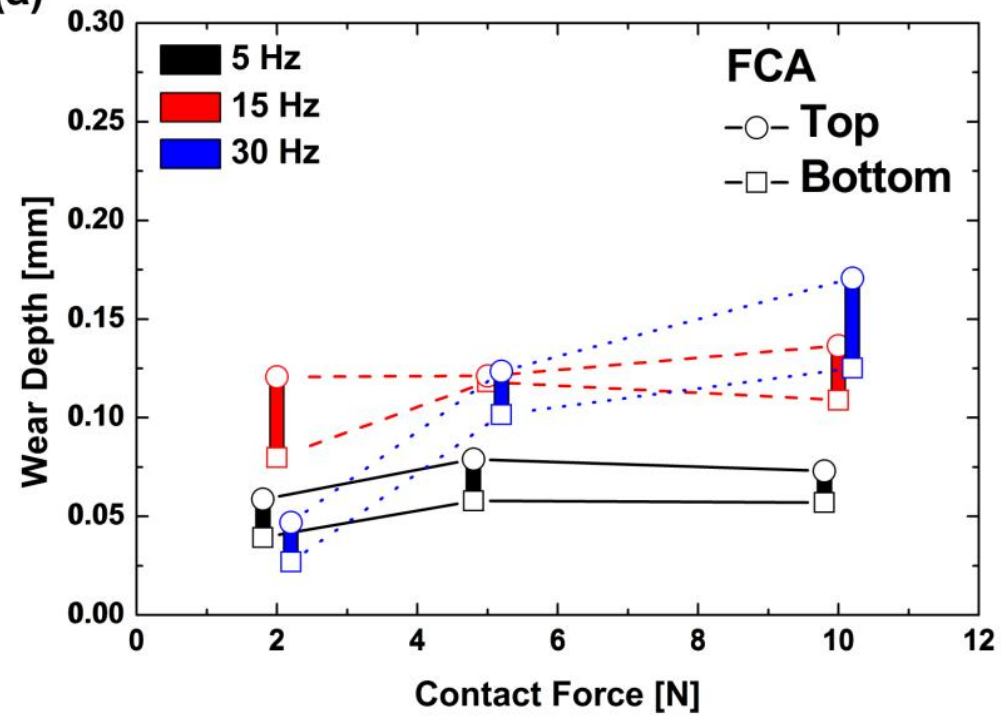

(b)

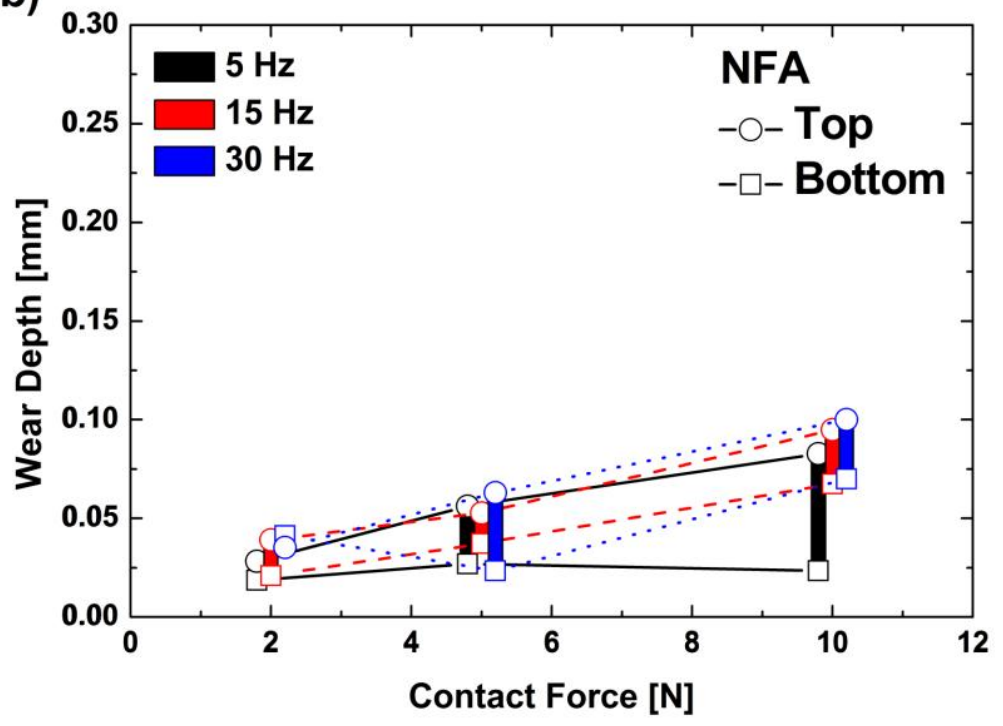




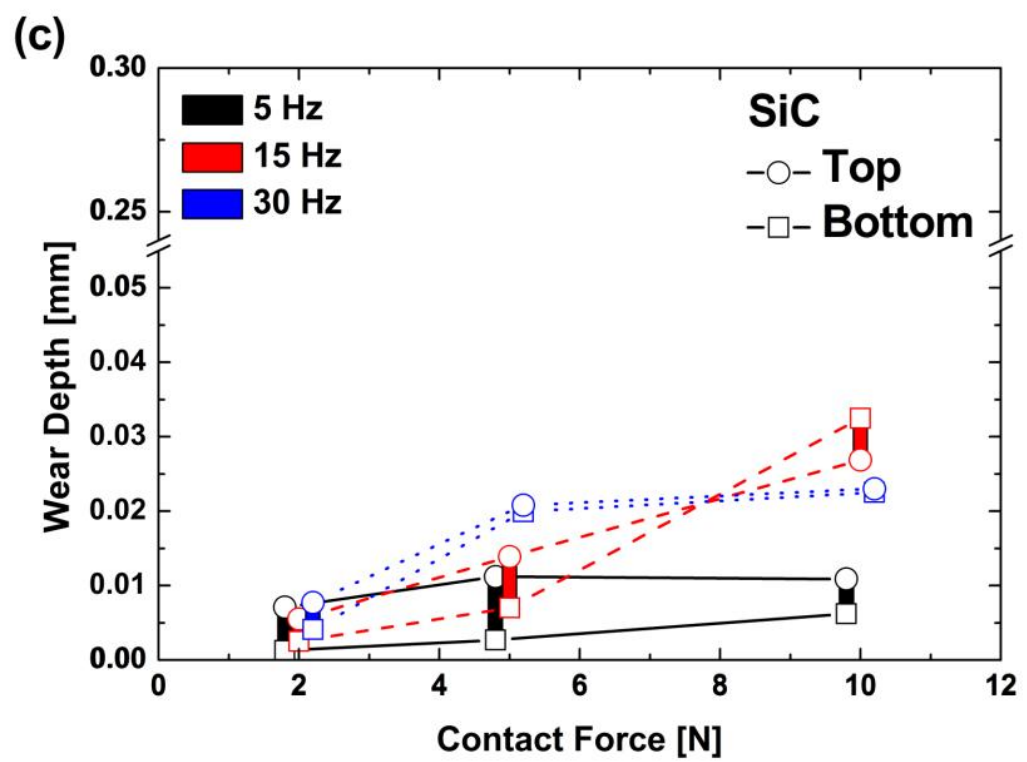

Fig. 4. Wear depth as a function of contact force and frequency in unlubricated condition between self-mated materials: (a) FeCrAl alloys; (b) Nano-structured ferritic Alloys; (c) $\mathrm{SiC} / \mathrm{SiC}$ composites. 
(a)

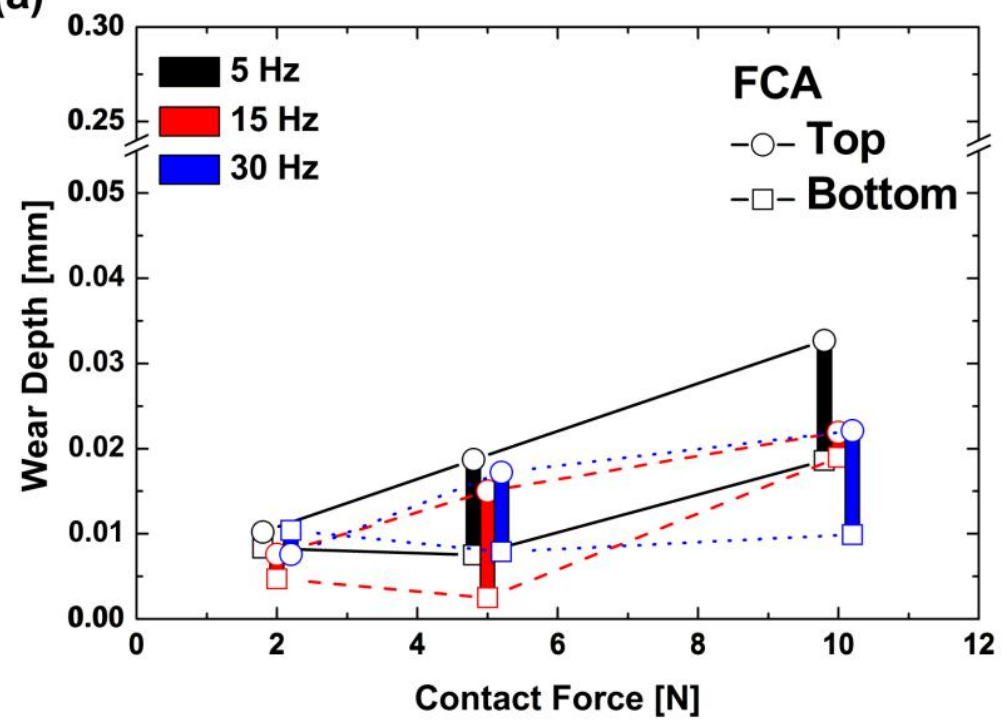

(b)

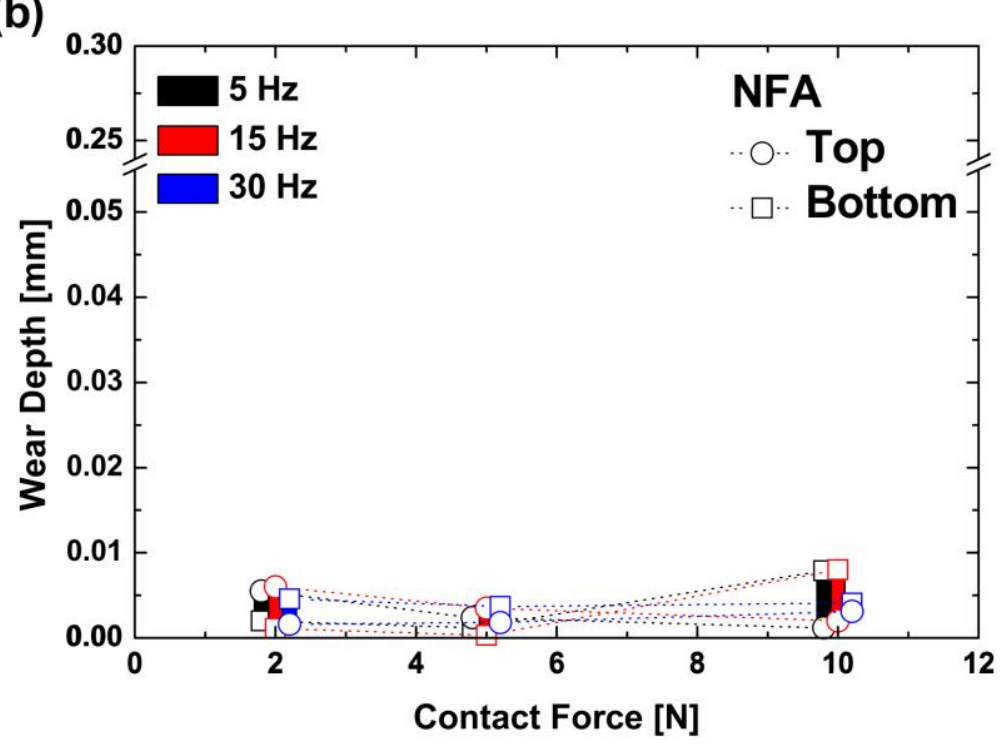




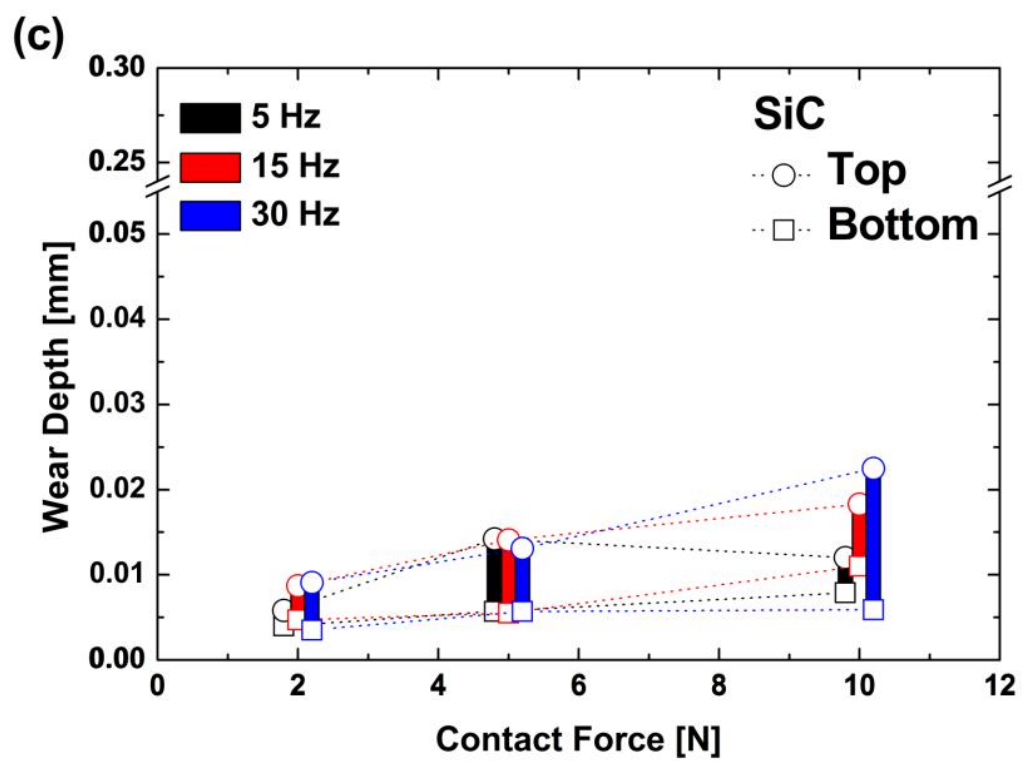

Fig. 5. Wear depth as a function of contact force and frequency under water lubrication between self-mated materials: (a) FeCrAl alloys; (b) Nano-structured ferritic Alloys; (c) $\mathrm{SiC} / \mathrm{SiC}$ composites. 


\section{(a) Unlubricated}

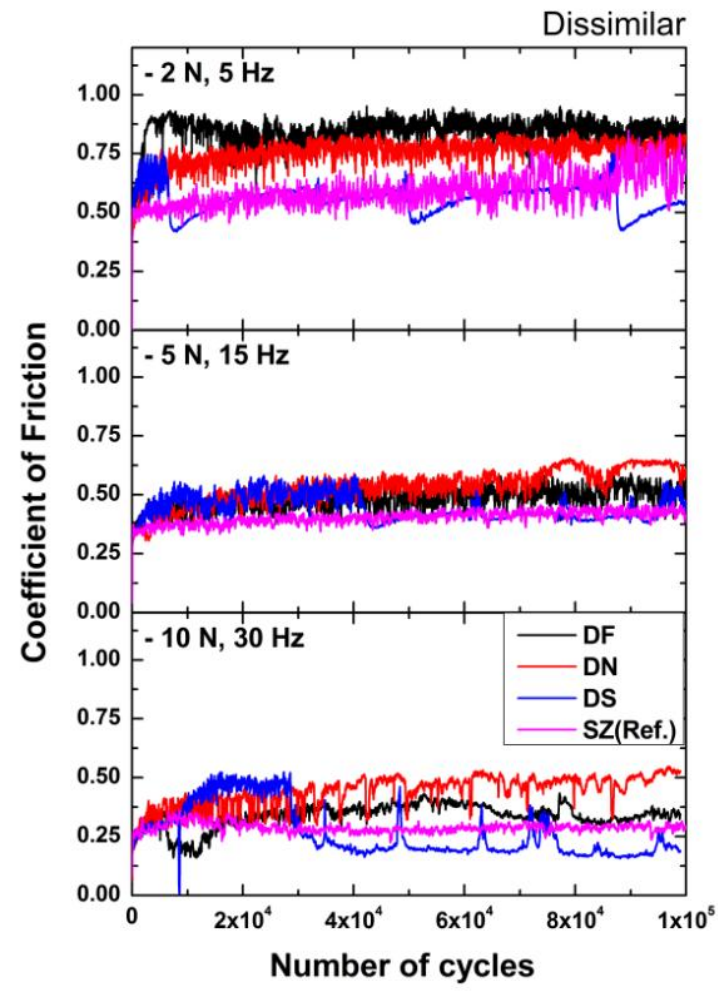

\section{(b) Water lubrication}

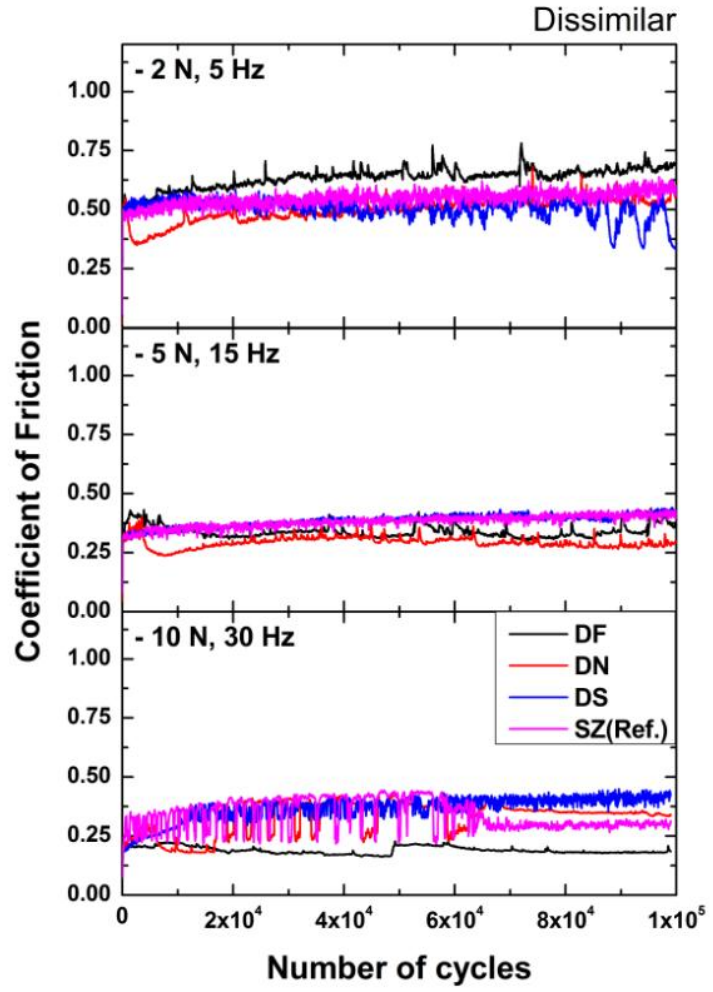

Fig. 6. Variation of coefficient of friction (COF) curves with increasing contact force and frequency between dissimilar materials: in (a) unlubricated and (b) water lubrication conditions. 


\section{(a) Unlubricated}

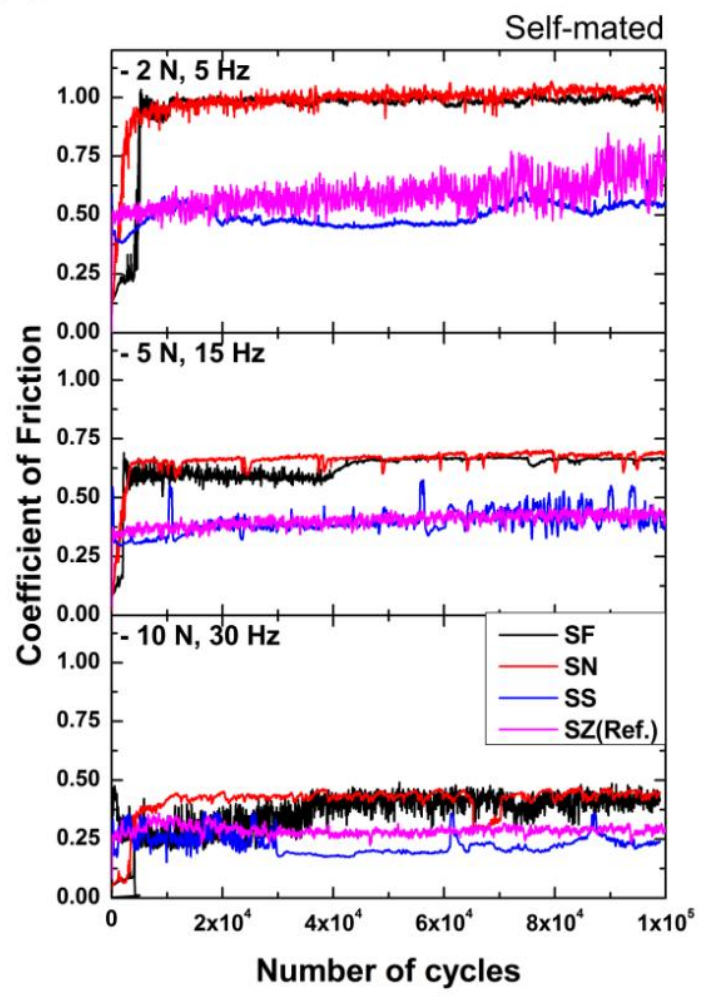

(b) Water lubrication

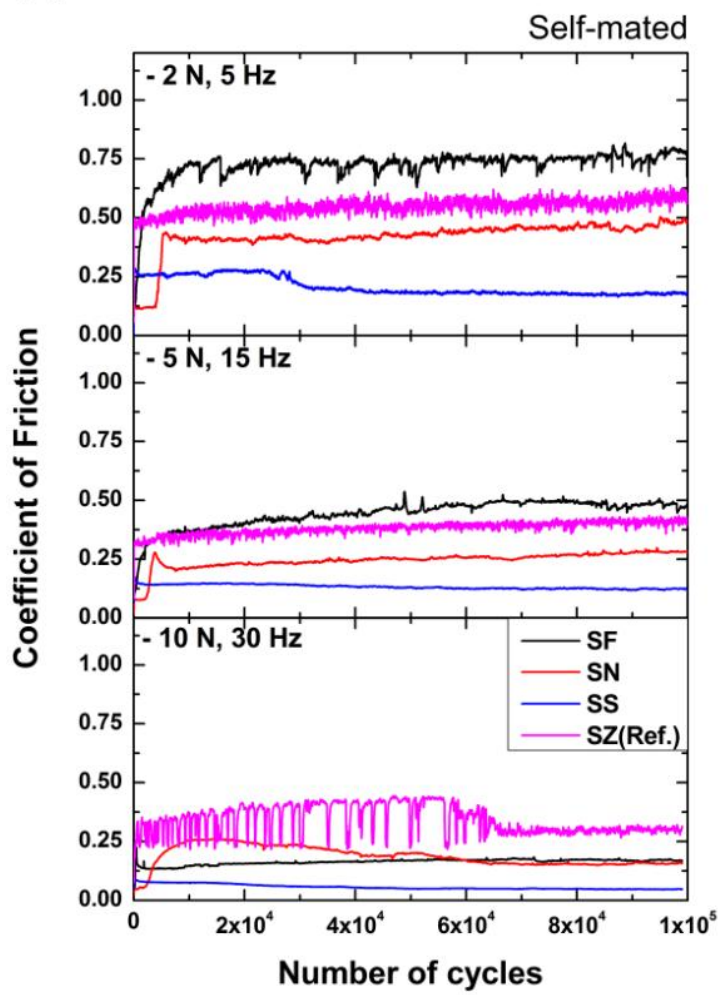

Fig. 7. Variation of coefficient of friction (COF) with increasing contact force and frequency between self-

mated materials: in (a) unlubricated and (b) water lubrication conditions. 

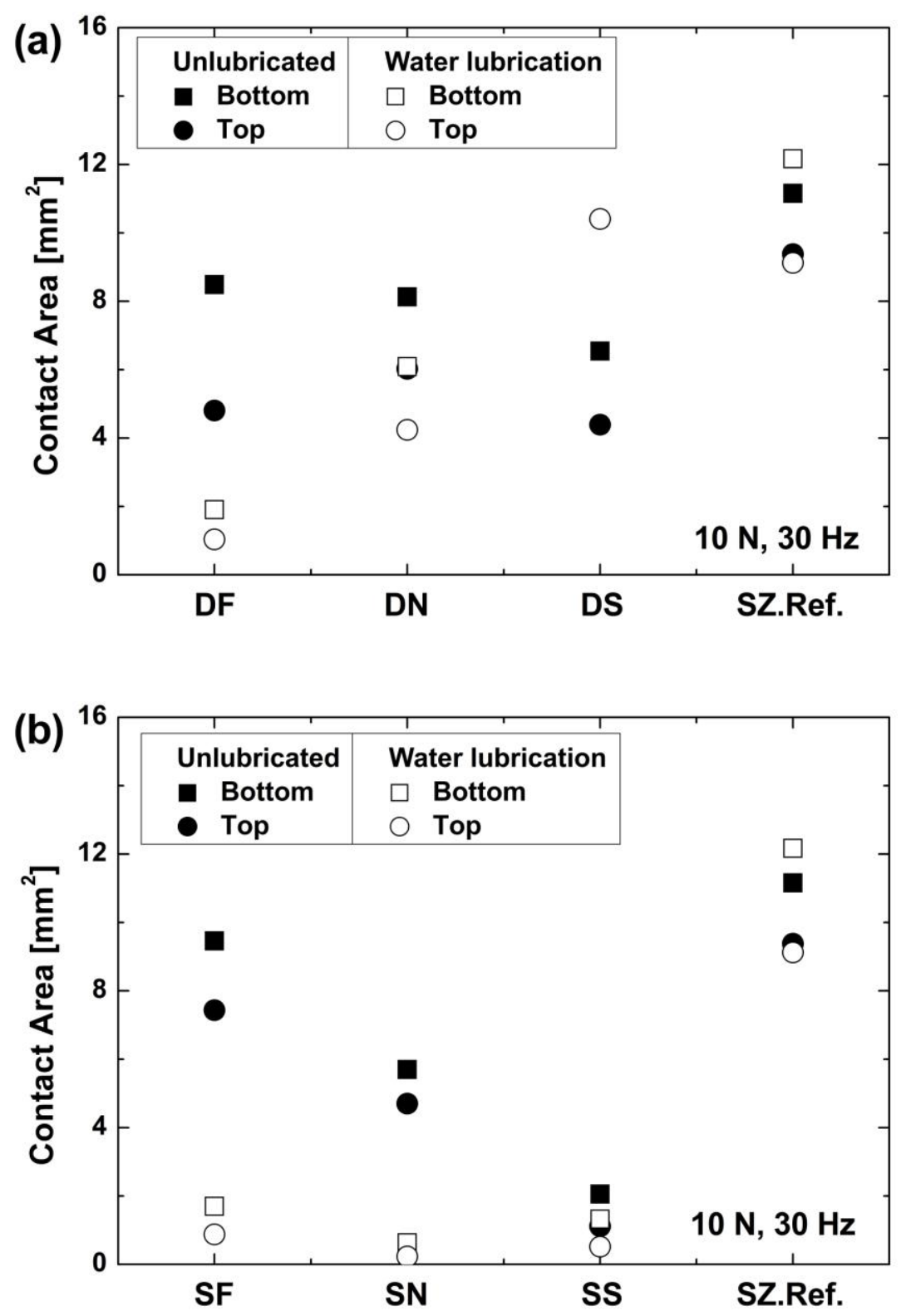

Fig. 8. Measurement results of contact area at each material combination at a contact force of $10 \mathrm{~N}$ and a frequency of $30 \mathrm{~Hz}$ : in couples of (a) dissimilar and (b) self-mated materials. 